Res Pública Revista de Historia de las Ideas Políticas

ISSN: $1131-558 \mathrm{X}$

https://dx.doi.org/10.5209/rpub.79721

\title{
República y poema
}

\author{
Sergio Villalobos-Ruminott ${ }^{1}$
}

Recibido: 06-03-2021 / Aceptado: 21-10-2021

Resumen. El materialismo salvaje desarrollado por Jacques Lezra no solo se opone a las cosmologías y ontologías modernas, articuladas en torno a un principio de organización de lo que hay, sino que también se expresa políticamente bajo la forma de un republicanismo salvaje que difiere no solo del republicanismo liberal sino también del llamado republicanismo normativo ilustrado. ¿De qué trata este republicanismo salvaje, abierto a la diferencia entre terror y terrorismo?, ¿qué consecuencias tiene su desmontaje de los presupuestos normativos y soberanos del pensamiento onto-político occidental? $\mathrm{Y}$, finalmente, ¿qué función/posición cumple/ocupa el poema, no solo el poema lucreciano, sino el poema en general (si hay tal cosa), para esta imaginación política aleatoria, defectiva y salvaje? Con estas preguntas procedemos a interrogar una de las múltiples aristas de un pensamiento concernido con la mundanidad del pensar, cuya relevancia parece ser evidente. Al final, incorporaremos algunas reflexiones sobre el poema de Néstor Perlongher, "Cadáveres" (1987), como caso de la proliferación lucreciana de lo que hay.

Palabras clave: Materialismo salvaje; republicanismo salvaje; terror; poema; proliferación.

\section{[en] Republic and Poem}

\begin{abstract}
Jacques Lezra's postulation of a savage materialism not only differs from modern cosmologies and ontologies articulated around an organizing principle of what there is, but it also manifests politically as a savage republicanism; a republicanism that differs from both the liberal and the normative model of republican order. What is at stake with this savage republicanism, and with its thematization of the difference between terrorism and terror? ¿What are the consequences of this savage republicanism's radical interrogation of the sovereign and normative fundaments of the onto-political western thought? And finally, what function/position fulfill the poem -not only Lucrecio's famous poem, but the poem at large (if there is such a thing)-, for this random, savage, and defective political imagination? With these questions we will proceed to interrogate one of the multiple dimensions of a thought, Lezra's, concerned with the worldly condition of thinking, whose relevance seems self-evident. At the end, we will incorporate some thoughts on Néstor Perlongher's poem "Cadáveres" (1987) as an instance of the Lucretian proliferation of what there is.
\end{abstract}

Keywords: Savage Materialism; Savage Republicanism; Terror; Poem; Proliferation.

Cómo citar: Villalobos-Ruminott, S. (2022). República y poema. Res Pública. Revista de Historia de las Ideas Políticas, 25(2), 97-108.

Llueve.

Que este libro sea pues, para empezar, un libro sobre la simple lluvia.

Malebranche se preguntaba «por qué llueve sobre el mar, los grandes caminos y las dunas», ya que esta agua del cielo que en otros sitios riega cultivos (lo cual está muy bien) no añade nada al agua del mar o se pierde en las rutas y en las playas.

No se tratará de este tipo de lluvia, providencial o contra-providencial.

Este libro trata muy al contrario de otra lluvia, de un tema profundo que corre a través de toda la historia de la filosofía y que ha sido combatido y reprimido tan pronto como ha sido enunciado: la «lluvia» (Lucrecio) de átomos de Epicuro que caen en paralelo en el vacío, la «lluvia» del paralelismo de los atributos infinitos en Spinoza, y de otros muchos más: Maquiavelo, Hobbes, Rousseau, Marx, Heidegger incluso, y Derrida.

Éste es el primer punto que, descubriendo de entrada mi tesis principal, querría poner de manifiesto: la existencia de una tradición materialista casi completamente desconocida en la historia de la filosofía: el «materialismo» (es imprescindible alguna expresión para demarcarlo en su tendencia) de la lluvia, la desviación, el encuentro y la toma de consistencia.

Louis Althusser, Para un materialismo aleatorio, 30-31.

\footnotetext{
University of Michigan

svillal@umich.edu
} 
1.

Nos permitimos empezar con esta hermosa figura althusseriana, la de la lluvia, en la medida en que ella no solo alude a Lucrecio, el poeta del De rerum natu$r a$, sino además, alude a una supuesta "tradición" que el mismo Althusser denomina "la corriente subterránea de un materialismo aleatorio". Por supuesto, no se trata de una tradición en el sentido fuerte, articulada por las figuras de la autoría y de la influencia, de la reconstrucción y de la organización conceptual, canónica, de los saberes; sino de una tradición enrevesada y soterrada. Una "tradición materialista" que, como mínimo, no puede ser ni oficial ni hegemónica, pues implica, en su propia existencia, un clinamen o una desviación con respecto a lo que podríamos llamar "la historia oficial", o "la tradición y el canon" de la filosofía, ya sea esta idealista o materialista, para usar esas nociones un poco "anacrónicas". Si esto fuese poco, no deja de impresionar el hecho de que Althusser coloque en ella, en medio de Lucrecio y Epicuro, de Maquiavelo y Marx, los nombres de Heidegger y Derrida. Esto no es menor y nos dice mucho sobre la forma en que Althusser lee el pensamiento heideggeriano y entiende la deconstrucción. Nos dice, por de pronto, que su materialismo aleatorio no es solo una hipótesis orientada a reflotar el materialismo dialéctico venido a menos con la estalinización y la subsecuente crisis del estalinismo, sino que apunta a una lectura a contrapelo tanto de la filosofía occidental, como de la política, y aún más, nos advierte que en el fondo, se trata de seguir pensando la misma relación entre filosofía y política, que desde la tesis 11 sobre Feuerbach al menos, se ha vuelto tanto enigmática como problemática ${ }^{2}$.

Uno debería insistir acá, aun cuando no nos alcance el tiempo, en el atrevimiento de Althusser de colocar al pensador de la "analítica existencial" y de "la pregunta por la técnica" en el horizonte de un materialismo que, a diferencia del materialismo vulgar e, incluso, a distancia del materialismo dialéctico, se concibe a sí mismo como un materialismo alternativo, atómico, heteróclito, "del encuentro". ¿Qué diría Heidegger de esta adjudicación?, ¿podríamos nosotros pensar la destrucción de la metafísica y la pregunta por el ser, con toda la supuesta revalidación mística del habitar y del cuadrante, como movimientos y estrategias constitutivas de un cierto gesto materialista? Y, para extremar aún más el caso, ¿cómo pensar el materialismo de Heidegger y su relación con Marx, a quien Heidegger le reconoce la capacidad de haber pensado, profundamente, la cuestión del "extrañamiento" como condición distintiva de la historia, solo para indicarnos que, a pesar de todo esto, Marx sigue

\footnotetext{
"Los filósofos se han limitado a interpretar el mundo de maneras diferentes, ahora lo que importa es transformarlo", en J. Muñoz (ed.) Marx, Barcelona, Ediciones Península, 1988, p. 433. La tesis sugiere la necesidad de "pasar a la acción" como imperativo de la práctica revolucionaria, pero deja indeterminada la misma relación entre la filosofía, esa que surge de la actividad distintiva de los filósofos, al menos hasta ese momento (los que se han dedicado a interpretar el mundo), y el mundo, es decir, deja en suspenso la supuesta articulación entre teoría y práctica. El materialismo aleatorio no se presenta como una sutura o articulación definitiva, sino como un pensamiento que habita en esa suspensión o indeterminación, de manera no prescriptiva.
}

preso de las determinaciones del materialismo metafísico, manifiestas en la centralidad del sujeto y del trabajo, como objetivación subjetivante del mundo $?^{3}$ ¿No es acaso el mismo Heidegger quien, entendiendo a Hegel como el máximo exponente de la onto-teología moderna, encuentra en Marx ciertos remanentes hegelianos que terminarían por limitar sus intuiciones? ${ }^{4}$

No olvidemos tampoco que el mismo Althusser, antes de la publicación de sus textos relativos al materialismo aleatorio, ingresa al debate teórico del marxismo europeo como defensor de la famosa "ruptura epistemológica" de Marx, la que habría ocurrido a fines de la década de 1850, y gracias a la cual, los remanentes historicistas y humanistas del joven Marx (de innegable procedencia hegeliana), habrían sido "superados". Ya sea contra Sartre o contra los resabios de un cierto idealismo hegeliano, la propuesta de un materialismo marxista depurado de toda huella humanista marcó la constitución de un campo analítico desarticulado de las figuras del sujeto soberano y del principio de razón con el cual se terminaba siempre reintroduciendo una lógica secuencial, evolutiva y archeo-teleológica. Esta suspensión de la lógica del fundamento le permitió a Althusser entreverarse con el carácter radicalmente contingente de lo real, y quizás sea pertinente introducir acá una diferencia entre la contingencia radical y lo que podríamos llamar una concepción convencional de contingencia, al modo de lo accidental o de lo imponderable, pues la contingencia radical ya no estaría sujeta al esquematismo aristotélico, el cual la determina desde la preponderancia de la "necesidad". Pensar la radicalidad de esta contingencia implica entonces entenderla no como una simple inversión de la necesidad, sino como una huida o substracción desde aquella formulación esquemática o categorial, es decir, como una contingencia en tensión con nociones como las de acontecimiento o accidente, siempre que estas últimas nociones también tienden a re-introducir, inadvertidamente, el mismo esquematismo binario de la metafísica desde donde el materialismo aleatorio o salvaje quiere salir ${ }^{5}$. En definitiva, bajo

"Eso que, partiendo de Hegel, Marx reconoció en un sentido esencial y significativo como extrañamiento del hombre hunde sus raíces en el desterramiento del hombre moderno. [...] Es precisamente porque al experimentar este extrañamiento Marx se adentra en una dimensión esencial de la historia por lo que la concepción marxista de la historia es superior al resto de las historias. [...] Claro que para eso también es necesario librarse de las representaciones ingenuas que se suelen tener del materialismo, así como de las críticas baratas que se le suelen echar en cara. La esencia del materialismo no consiste en la afirmación de que todo es materia, sino, mas bien, en una determinación metafísica según la cual todo ente aparece como material de trabajo. La concepción metafísica moderna de la esencia del trabajo ha sido pensada ya con antelación en la Fenomenología del espíritu de Hegel como el proceso que se dispone a sí mismo de la producción incondicionada, es decir, como objetivación de lo efectivamente real por parte del hombre, experimentado este como subjetividad". M. Heidegger, Carta sobre el humanismo, trad. Helena Cortés y Arturo Leyte, Madrid, Alianza editorial, 2013, p. 58.

4 Jacques Derrida retoma todas estas preguntas y las elabora aún más en el marco de su curso sobre Ser y tiempo. Cf. J. Derrida, Heidegger: The Question of Being and History, trad. Geoffrey Bennington, Chicago, The University of Chicago Press, 2016, pp. 21-24.

Piénsese, por ejemplo, en las formas en que la cuestión de la contingencia aparece en el pragmatismo de Richard Rorty o en la reconstrucción post-marxista del marxismo occidental de Ernesto Laclau y Chantal Mouffe. R. Rorty, Contingencia, ironía y solidaridad, Bar- 
las argucias de la sobredeterminación y de la coyuntura, Althusser se mostraba, desde el comienzo, como un pensador de la contingencia y, por lo tanto, como un pensador de lo político cercano a la invención maquiavélica de la indeterminación radical ${ }^{6}$, cuestión que sus escritos tardíos o inéditos confirman y, en el mejor de los cosas, profundizan.

Me interesan estos antecedentes -los que solo puedo esbozar preliminarmente acá- por dos razones puntuales: en primer lugar, porque quiero relativizar la tesis sobre una cierta discontinuidad entre un primer Althusser, relacionado con su obra publicada y con su función intelectual y su militancia política en los años 1960 y 1970; y lo que sería un Althusser tardío u oculto, figura relacionada con la publicación de sus Escritos filosóficos $y$ políticos y con su formulación del materialismo aleatorio $^{7}$. Pero, más allá de esta pequeña querella, la que tiene importantes consecuencias a las que no podré atender acá ${ }^{8}$, me interesa también, y en segundo lugar, hacer referencia a este horizonte problemático porque es en él donde debemos, en primera instancia (y para efectos de nuestra reflexión) inscribir el trabajo de Jacques Lezra. En otras palabras, la particular recepción de Lucrecio y la consecuente elaboración de un "materialismo salvaje" por parte de Lezra, encontrarían "domicilio" de manera natural en la tradición esbozada por Althusser. Lezra precipitaría, en tal caso, una inflexión y una anexión al interior de esta corriente subterránea, la que se haría relevante ahora, como alternativa a la racionalidad populista que sigue alimentando el imaginario progresista en América Latina y en otros lados, en los últimos años ${ }^{9}$.

Por supuesto, el justificado revival del pensamiento althusseriano en la actualidad no hace sino complejizar aún más las cosas, en la medida en que, ya sea en la

celona, Ediciones Paidós, 1991. También, E. Laclau \& Ch. Mouffe, Hegemonía y estrategia socialista. Hacia una radicalización de la democracia, Madrid, Siglo XXI, 1987. Faltaría sin embargo pensar las tensiones entre la cuestión de la contingencia radical y la cuestión del acontecimiento en Alain Badiou, por ejemplo.

6 Por supuesto, aquí habría que considerar no solo los volúmenes que Althusser dedicó a Maquiavelo y a la filosofía política clásica, sino el revival de los estudios sobre el florentino en la línea althusseriana. Por ejemplo, cf. L. Althusser, "Contradicción y sobredeterminación" (notas para una investigación)", en La revolución teórica de Marx, trad. M. Harnecker, México, Siglo XXI, 1968, pp. 71-106. Cf. también, L. Althusser, Écrits philosophiques et politiques, 2 Tomes, $\mathrm{Pa}$ ris, Éditions STOCK/IMEC, 1994. Y su famosa conversación con Fernanda Navarro: L. Althusser, Filosofia y marxismo. Entrevista por Fernanda Navarro, Madrid, Siglo XXI, 2005.

8 Entre ellas, y para nada menores, acá se halla la posibilidad de oponerse a la clausura del pensamiento althusseriano en la figura de un mandarín elitista, de un caimán jerárquico, que se desprende del texto de J. Rancière, La lección de Althusser, Buenos Aires, Libros del Zorzal, 2008. Como también, la posibilidad de relativizar la recepción de Althusser en la formulación de una concepción post-marxista de la política, regida por la llamada "lógica de la contingencia" en E. Laclau \& Chantal Mouffe, Hegemonía y estrategia socialista, op. cit.

9 Con "racionalidad populista", no me refiero solo a E. Laclau, La razón populista, Buenos Aires, Fondo de Cultura Económica, 2010, sino a la re-emergencia de una serie de movimientos neo-populistas de izquierda en diversas partes del mundo, como alternativa a las políticas neoliberales. Cf. también, Ch. Mouffe, For a Left Populism, London, Verso, 2018, y su impacto en Podemos, en España, así como también en diversos grupos progresistas asociados con la llamada Marea Rosada latinoamericana, para no hablar de los populismos de derecha que con Marie Le Pen, Donald Trump, Jair Bolsonaro y sus secuaces, asolan el mundo. recepción ejemplar de Warren Montag ${ }^{10}$, o en el trabajo de un cierto marxismo italiano relativo a la cuestión de la pluritemporalidad marxiana ${ }^{11}$; ya sea en la perseverancia de Étienne Balibar, o en el sostenido trabajo de varios estudiosos latinoamericanos ${ }^{12}$, dicho revival complejiza la escena de recepción y de lectura convencional, obligándonos a considerar detenidamente cómo este materialismo aleatorio implica también una práctica no convencional de lectura y de organización del horizonte problemático contemporáneo. No se trata entonces de afirmar algo así como una relación analógica o una convergencia superficial entre el horizonte althusseriano y el trabajo de Lezra, sino de inscribir a ambos en esta "tradición" para poder atender en propiedad a la singularidad de lo que, con Lezra, aparece bajo las figuras de un republicanismo salvaje, habilitado en una onto-poética heteróclita y en una filología negativa, capaz de atorar o interrumpir la equivalencia general que posibilita la circulación ampliada contemporánea de mercancías y de teorías, mientras se presenta como una alternativa atendible al predominio epocal de la racionalidad populista.

\section{2.}

El trabajo de Lezra debe su complejidad no solo ni principalmente a la condición erudita y elaborada de sus argumentos, ni menos a la forma heterogénea de su despliegue (hispanista, comparatista, renacentista, marxista, etc.), además de todo esto, se trata de un pensamiento complejo por su composición un tanto aleatoria y por su misma afirmación relativa al mundo, en la forma de una ontología materialista y atómica, no subordinada a las decisiones de una subjetividad final o de un principio de razón. Sus libros parecieran poner en escena (to perform) sus mismas ideas, las que insisten en mostrar la condición aleatoria y contingente de un mundo que se sostiene sobre sí mismo, una vez hemos restado las pretensiones de una fundamentación trascendental o transhistórica. Ya sea que hablemos de su Materialismo salvaje, de su monografía sobre las cosas de Marx, de su reflexión sobre el estado actual de las humanidades en el contexto de la globalización neoliberal y su permanente reducción de la complejidad, o de su último volumen, República salvaje, lo cierto es que su trabajo opera abriendo caminos de pensamiento, más allá de las piedades pedagógicas demandadas por el lector convencional, y más allá de la pretensión de poseer un sistema conceptual acabado e infalible ${ }^{13}$. Hay que atender enton-

10 W. Montag, Althusser and His Contemporaries: Philosophy's Perpetual War, Durham, Duke University Press, 2013.

11 Me limito a solo una referencia: V. Morfino, El materialismo de Althusser, Santiago de Chile, Palinodia, 2014.

12 Por ejemplo, M. Rodríguez Arriagada \& M. Stacerbaun (eds.), en Lecturas de Althusser en América Latina, Santiago de Chile, Doble Ciencia, 2017.

13 Cf. J. Lezra, Materialismo salvaje. La ética del terror y la república moderna, trad. J. Rodríguez Fernández, Madrid, Biblioteca Nueva, 2012. Además de, Untranslating Machines: A Genealogy for the Ends of Global Thought, Londres, Rowman and Littlefield, 2017. Como también su On the nature of Marx's Things, New York, Fordham University Press, 2018. Y, el reciente volumen titulado República Salvaje, Santiago, Ediciones Macul, 2019. 
ces a la condición salvaje de este pensamiento, el que no solo tematiza el desorden constitutivo del mundo, como una apuesta sin garantías, sino que se evade de cualquier pragmática de la comunicación, para restituir la dignidad material de lo complejo frente a las simplificaciones operadas por el capital.

Quisiera, sin embargo, enfocarme acá en algunos elementos centrales de este materialismo salvaje. En efecto, con el trabajo de Lezra estamos frente a un pensamiento que emerge bajo la forma de una afirmación ontológica, epistemológica y política. La referencia central al De rerum natura de Tito Lucrecio Caro no puede ser exagerada en la medida en que Lezra parece hacer reposar en Lucrecio una lectura que podría ser fácilmente malentendida como anacrónica. La anacronía, en tal caso, no es solo un efecto involuntario de su potente lectura, sino la característica distintiva de su procedimiento filológico particular, que no se subordina a los criterios historicistas y evolucionistas que definen el horizonte de los estudios clásicos. En otras palabras, sin cierto grado de anacronía solo habría historicismo y estética de la recepción ${ }^{14}$.

El poema lucreciano sirve entonces para abrir una cierta desviación ontológica y epistemológica en la metafísica occidental de corte platónico-aristotélico, cuestión que permite, a su vez, postular una genealogía de lo político que no se clausura ni en las determinaciones de la ontología clásica, de la teología medieval o de la ciencia moderna. Lucrecio aparece como una alternativa -no heideggeriana- a la crítica de la onto-teología occidental, apuntando hacia una ontología material y atómica que se resiste tanto a la lógica del fundamento como a la misma operación de determinación característica de toda ontología atributiva ${ }^{15}$. En otras palabras, el materialismo salvaje habilita la dimensión de una contingencia radical relacionada con la figura de la caída, del encuentro, de la catástrofe y del clinamen, como formas de la variación o de la diferenciación, que escapan a la dialéctica de la identidad y la diferencia, a la dicotomía de la necesidad y la contingencia y, en general, al principio de razón que organiza el esquema conceptual de la metafísica entendida de este modo. Por supuesto, aquí habría que tener presente la forma en que este materialismo de Lezra, salvaje y proliferante, ya no puede ser re-unido (según el versammeln heideggeriano) bajo la proposi-

\footnotetext{
Más allá del lugar central que ocupa Lucrecio en sus libros Materialismo salvaje y República salvaje, cuyo subtítulo es, precisamente, "De la naturaleza de las cosas", y de la monografía titulada De la naturaleza de las cosas de Marx, en clara alusión al libro de Lucrecio, De rerum natura, vertido al español como De la naturaleza de las cosas, hay que tener en consideración el siguiente volumen: J. Lezra \& L. Blake, (eds.), Lucretius and Modernity: Epicurean Encounters across Time and Disciplines, New York, Pelgrave Macmillan, 2016. Un volumen orientado productivamente gracias a la misma anacronía. Para una tematización alternativa y complementaria de la cuestión de la anacronía, cf. G. Didi-Huberman, Ante el tiempo. Historia del arte y anacronismo de las imágenes, trad. A. Oviedo, Buenos Aires, Adriana Hidalgo Editora, 2006.

15 Por supuesto, estas referencias tienen una función meramente indicativa, no concluyente ni tampoco normativa, en la medida en que tanto la tradición platónico-aristotélica como la llamada onto-teología están siendo siempre repensadas y "deconstruidas" desde su propio “interior”, cuestión que complejiza toda comprensión monolítica o concluyente al respecto.
}

ción ni de una ontología fundamental, ni mediante la determinación substancial de la ratio como techné y dominación tecnológica planetaria. La proliferación, una figura constitutiva -como la lluvia-, de la corriente subterránea del materialismo del encuentro, encontrará en Deleuze una actualización decisiva ${ }^{16}$, la que junto a las nociones de constelación y de dispersión (diseminación y scatterinig), se oponen a la re-inseminación de la metafísica del hogar (Heimat) y de la re-unión o reunificación (versammeln) que caracterizaría a la lectura heideggeriana del poema ${ }^{17}$.

Gracias a esta destitución de la ontología estructurada según una comprensión archeo-teleológica del tiempo y remitida a la función de fundamento, Lezra puede concebir un republicanismo material que parece resistir su sobre-codificación moderna, ya sea en los términos de una lógica soberana y fundacional (sea esta la soberanía del Estado o la llamada soberanía popular), ya sea en los términos de un republicanismo orientado normativamente, según valores y normas definidos intersubjetivamente de acuerdo con principios cuasi-trascendentales de racionalidad normativa ${ }^{18}$. Para decirlo de forma alternativa: en el debate político contemporáneo, el orden republicano sigue estando enmarcado, por un lado, por la condición soberana e indivisible del poder del Estado y sus criterios de pertenencia y adscripción, o por la caracterización del pueblo como depositario último e indivisible de la soberanía popular y su legitimidad (autoridad). Incluso, las teorías cosmopolíticas más radicales (aunque indefectiblemente europeas), siguen pensando el orden republicano internacional según alguna variable de la famosa "federación de naciones" kantiana, es decir, según una imagen de la república "fundada" en

\footnotetext{
La cuestión de la proliferación aparece insistentemente en el trabajo de Gilles Deleuze, desde sus primeras monografías hasta sus textos en colaboración con Félix Guattari. Me limito ahora a G. Deleuze, Lógica del sentido, Barcelona, Paidós, 2005. En este volumen, además, se retoma, de manera central, la cuestión del materialismo antiguo en consonancia con las referencias de Lezra.

17 Toda esta economía topológica y tropológica del hogar y de la reunión, pero también de la dispersión, la errancia y la proliferación, el scattering, y la diseminación, está absolutamente presente en el debate contemporáneo, pero me limito al recientemente publicado volumen de Derrida sobre la lectura heideggeriana de la poesía de Georg Trakl (realizada en 1953 en su "Die Sprache im Gedicht. Eine Erörterung von Georg Trakls Gedicht.") que apareció como Geschlecht III, texto que complementa la serie de 4 Geschlecht que Derrida dedicó a la filosofía de Heidegger. Cf. J. Derrida, Geschlecht III. Sexe, race, nation, humanité, Paris, Seuil, 2018. He puesto "caracterizaría" porque otra lectura es posible, como nos indica F. Dastur, "Heidegger y Trakl: el paraje occidental y el viaje poético", Escritura e imagen, 12, 2016, 249-266, y su "Heidegger and Derrida on Trakl", en Pol Vandevelde (ed.), Phenomenology and Literature: Historical Perspectives and Systematic Accounts, Würzburg: Koenighausen \& Neumann, 2010, pp. 43-57.

18 Por supuesto, esta fundamentación cuasi-trascendental, que también resuena en Derrida, no puede ser simplemente despachada. Por el contrario, lo que intento sostener con este argumento es la pertinencia de una posible contrastación entre el republicanismo salvaje y la "reconstrucción" del materialismo histórico como fundamento material para una pragmática comunicativa universal en la que fundar la democracia post-liberal, en Jürgen Habermas. Cf. J. Habermas, La reconstrucción del materialismo histórico, Madrid, Taurus, 1981. A la vez, es esperable que en su anunciado volumen sobre las instituciones defectivas, Lezra insista sobre esta importante dimensión del problema. Además, habría que insistir, la cuestión misma de lo cuasi-trascendental merece mayor atención.
} 
las prerrogativas de un derecho constitucional marcadamente inscrito en la concepción moderna del Estado, de la comunidad y de la ciudadanía (que son, a su vez, los mojones teológico-políticos de la pertenencia, la identidad y la diferencia), y cuya fundamentación última se hallaría en la historicidad singular de la modernidad europea, en su razón, en su conciencia y en su ciencia ${ }^{19}$. Si no atendemos a este horizonte histórico y normativo, se argumenta, correríamos el riesgo de caer definitivamente en las lógicas del "nuevo nomos de la tierra", ahora articulado planetariamente, o sea, más allá de la postguerra europea que llevó a Carl Schmitt a pensar en la crisis del Jus Publicum Europaeum a comienzos de los años $1950^{20}$. En efecto, nuestro horizonte estaría decididamente marcado por el fin de la Guerra Fría, por la expansión de la llamada Pax Americana ${ }^{21}$ y por la redefinición geopolítica del mundo como escenario para una guerra global de intensidad flexible ${ }^{22}$.

Sin embargo, como es fácil de adivinar, este republicanismo -y su cosmopolitismo complementario- siguen atrapados en la tradición onto-política moderna, la que no puede renunciar a los presupuestos antropológicos y biopolíticos del orden social. Sería contra estas amarras normativas y auto-referenciales que el republicanismo salvaje cobraría mayor relevancia, en la medida en que hace posible una concepción de la relación entre soberanía y violencia, entre terror y terrorismo, inédita para esta tradición. En otras palabras, la condición inanticipable o incalculable del terror como violencia insosegable en el trabajo de Lezra ${ }^{23}$, no solo funciona como antídoto contra la operación pacificadora y la sutura normativa del orden social (las diversas versiones de la paz perpetua europea) emprendida por el liberalismo clásico y por sus variantes republicanas, sino también como develación de la condición inescapable de la violencia y del poder en la misma constitución contingente del agregado social, bajo la ficción del pacto y de la ley ${ }^{24}$. La diferencia entre terror y terrorismo, en este sentido, habita el mismo horizonte problemático abierto por Walter Benjamin y su diferenciación de la violencia divina y la violencia mítica, cuestión críticamente revisitada por Jacques Derrida en Fuerza de ley ${ }^{25}$. Se trata tanto de un

19 Aunque aquí - vale la pena dejarlo consignado- es donde habría que pensar tanto la cuestión misma de la democracia à venir derridiana, como el desarrollo de un "constitucionalismo post-nacional" y de un "patriotismo de las instituciones" que el incansable Habermas comienza a pensar después de los 1980 .

20 C. Schmitt, The Nomos of the Earth in the International Law of Jus Publicum Europaeum, trad. G. L. Ulmen, New York, Telos Press Publishing, 2006.

21 W. Spanos, American Exceptionalism in the Age of Globalization: The Specter of Vietnam, New York, SUNY Press, 2008.

22 C. Galli, Political Spaces and Global War, trad. E. Fay, Minneapolis, University of Minnesota Press, 2010.

23 Materialismo salvaje, op. cit. Cf., en particular, la presentación a cargo de Étienne Balibar "La metamorfosis de la pulsión de muerte", pp. 11-23.

24 Decimos agregado social y no "sociedad". La sociedad como tal, responde más bien a las teorías normativas del orden social en el periodo de surgimiento de la primera sociología europea, la que a su vez, hereda e historiza los presupuestos de las teorías contractualistas clásicas, en particular, la postulación de una antropología hipotética y un "estado de naturaleza" a ser corregido o limitado por el derecho.

25 Ver los conocidos textos de W. Benjamin, "Para una crítica de la violencia", en Para una crítica de la violencia y otros ensayos. Ilu- cuestionamiento de la ficción soberana, como de una deconstrucción de sus binarismos: orden/anarquía, paz/ guerra, seguridad /terror, etc.

Decíamos anteriormente que este republicanismo salvaje resultaba central para salir de las paradojas de la soberanía (su indivisibilidad y su homologación con las nociones cuasi-teológico-políticas del Estado o del Pueblo), sobre todo pensando en la arremetida de los populismos de derecha e izquierda en la actualidad. En este contexto, no deja de ser llamativo que, como antídoto contra dichos populismos, se suela invocar la necesaria reconstitución de un republicanismo basado en un horizonte normativo común, una especie de Sittlichkeit o eticidad hegeliana que se materialice en un sistema jurídico (una Constitución) capaz de prevenir o inmunizar al orden frente a las arremetidas populistas, inmunizando de paso al sistema político de las demandas sociales ${ }^{26}$. La paradoja acá es la siguiente: si la república se mantiene abierta a los procesos sociales instituyentes, la república misma pareciera desvirtuarse gracias a su subordinación a las demandas populares/populistas; pero si, por el contrario, la república se abasteciera de una legislación inmunitaria o preventiva, entonces se mantendría a salvo de las demandas sociales y del populismo, aunque solo para convertirse en un sistema juristocrático cerrado $\mathrm{y}$ autorreferente ${ }^{27}$.

El republicanismo salvaje, entonces, parte por desplazar la tensión entre populismo soberanista y republicanismo jurídico-normativo, para hacer posible una "filosofía política" basada en un concepto de orden social ajeno al pensamiento normativo, anclado en la capacidad instituyente, pero secular, de un agregado social que se provee así mismo de instituciones transitorias, para-instituciones o "instituciones defectivas", como el mismo Lezra indica, las que, funcionando como prótesis circunstanciales o contingentes, no son ni sacralizables, ni pueden ser revestidas o investidas con una teoría convencional de la soberanía. Esto implica que lo social ya no remite ni a la configuración de formas colectivas "masivas o molares" de representación de un orden deseado ni a las determinaciones normativas y valóricas de la cultura y las costumbres de "un" pueblo, sino a la agregación contingente de prácticas y acciones que no solo rompen con los presupuestos fundacionales de las sociologías normativas, sino que también nos devuelven a la cuestión del con-

minaciones $I V$, trad. R. Blatt, España, Taurus, 1991. 24-46. Y, J. Derrida, Fuerza de ley. El "fundamento místico de la autoridad", trad. P. Peñalver y A. Barberá, Madrid, Tecnos, 2008.

26 Para un análisis documentado de la forma constitucional en América Latina, atendiendo a estas variables, ver R. Gargarella, La sala de máquinas de la constitución, Buenos Aires, Katz Editores, 2014. Para un análisis de las formas en que el constitucionalismo actual funciona de forma auto-inmunitaria o juristocrática, cf. R. Hirschl, Towards Juristocracy. The Origins and Consequences of the New Constitutionalism, Cambridge, Massachusetts, Harvard University Press, 2007.

27 Quizás esta sea la tensión distintiva del progresismo contemporáneo, la tensión entre republicanismo y populismo que, como tal, se muestra como una falsa tensión tan pronto como sus presupuestos normativos o soberanos son desplazados. Permítasenos referir S. Villalobos-Ruminott, "Acerca de la posibilidad de una democracia salvaje", Pensamiento al margen, $\mathrm{N}^{\mathrm{0}}$ especial: Infrapolítica y democracia, 2018, pp. 33-63. 
tagio, la imitación (Gabriel Tarde), la afección y las formas aleatorias de los ensamblajes sociales (Deleuze \& Guattari), pensados desde la in-corporación (como plegamiento) y desde la participación (como acoplamiento), sin teleología ni fundamento ${ }^{28}$.

Finalmente, nos gustaría reparar en el hecho de que este republicanismo salvaje sería capaz de abastecerse a sí mismo de instituciones defectivas o transitorias, incapaces de ser investidas soberanamente, al modo de prótesis que soportan la existencia en común, por lo cual podría ser pensado en relación con la tradición del pensamiento instituyente, o con la noción de imaginación instituyente desarrollada por Cornelius Castoriadis, siempre y cuando el magma que abastece a esta imaginación, para el pensador griego, se disuelva en un ensamblaje o "lluvia de partículas o átomos indeterminados", cuyo modelo estaría en la física y en la cosmología atomista clásica, y su resistencia a las cosmogonías principiales o teológicas ${ }^{29}$. En ultima instancia, la condición salvaje del republicanismo tiene que ver no solo con la condición desacralizada del orden institucional, sino también con la denuncia de y la renuncia a los remanentes o mojones teológico-políticos del pensamiento occidental, en las figuras del Estado, de la soberanía y de la ley, pero también es sus infinitas instituciones de reproducción y perpetuación (familia, escuela, lengua, constitución, ciudadanía, identidad, pertenencia, matrimonio, pedagogía, etc.).

Aquí radicaría entonces una de las propuestas más importantes del trabajo de Lezra, puesto que pensar en instituciones débiles implica, por supuesto, cuestionar la noción moderna de soberanía y sus aspectos autárquicos y solipsistas, sin caer en la tentación de restituir la hipótesis del contrato inmemorial y su pretendida "transferencia voluntaria". Se trata de asumir que la deconstrucción misma de la soberanía, si así pudiésemos decirlo, no implica su superación (ya siempre soberana), sino su inscripción en una economía de fuerzas que estructura las formas del vínculo social, sin promesas ni romantización del orden o de la paz. En este sentido, el republicanismo salvaje implica un abandono radical del paradigma de la seguridad, desde Hobbes a las biopolíticas securitarias y "propietaristas" contemporáneas, subvirtiendo de esta forma la alianza endémica entre liberalismo económico y teoría del gobierno civil ${ }^{30}$.

\footnotetext{
En oposición a las grandes representaciones sociales, elaborada por la sociología clásica à la Durkheim, acá cabría la referencia a Gabriel Tarde y su elaboración del contagio y la imitación, cf. G. Tarde, Monadología y sociología, Buenos Aires, Cactus, 2012. La cuestión del pliegue y de la monadología, resaltadas por G. Deleuze (El pliegue. Leibniz y el barroco, trad. J. Vázquez y U. Larraceleta, Barcelona, Paidós, 1989), están en la misma línea y resultan centrales para pensar el republicanismo salvaje más allá de cualquier restitución normativa de la cuestión del lazo social y de la "representación", y para pensarlo también en relación con la cuestión del poema lucreciano.

29 C. Castoriadis, La institución imaginaria de la sociedad, trad. A. Vicens y M. A. Galmarini, Barcelona, Tusquets, 2013.

30 Se trata entonces de inscribir este republicanismo salvaje en el corazón de la biopolítica occidental, y sus procesos de securitarización e inmunitarización de la vida. Cf. R. Esposito, Immunitas. Protección y negación de la vida, trad. L. Padilla López, Madrid, Amorrortu, 2004.
}

3.

Sin embargo, todo esto que hemos presentado de manera un tanto abrupta, nos permite ahora plantear algunas observaciones y preguntas relativas al estatuto del poema, tanto en el pensamiento de Lezra, esto es, el estatuto del De rerum natura y su "función" ilustrativa, ejemplar, fundacional o referencial para el despliegue de su "filosofía política" y de su teoría de las instituciones; como con respecto al estatuto del poema en general, en relación con la cuestión del lenguaje y de su función apofántica o logocéntrica en la lectura que pudiera hacerse desde la misma "filosofía política". ¿Cómo pensar la tensión entre ontología y poema? Si cabe esta pregunta, y ¿hasta qué punto la inscripción anacrónica del De rerum natura reinstituye una relación determinativa para el poema? O, alternativamente, ¿hasta qué punto la ingobernabilidad o anarquía (an-arché) constitutiva de su cosmo-logía, hace imposible la función determinativa, debilitando toda ontología según la economía principial de las épocas distintivas de la metafísica (entendida como onto-teo-logía), haciendo aparecer la pretensión de una nueva "filosofía política" como una vacilación o un impensado, que no está a la altura de los mismos desplazamientos constitutivos de este materialismo?

Frente a estas preguntas nos atrevemos a tomar una posición clara (aunque no necesariamente cerrada). Creemos que el materialismo salvaje no constituye, salvo al nivel performativo y circunstancial, una "filosofía política" ni se inscribe en lo que tal filosofía quisiera demarcar, ya sea que hablemos de una filosofía política de corte francés o anglosajón, o incluso de una filosofía política alimentada por los desarrollos de la llamada historia conceptual, pero auto-limitada por una preocupación disciplinaria con la política. El materialismo salvaje, antes que una filosofía política, es una suspensión de la misma diferencia entre filosofía y política, pero no al modo de una refundación aleatoria de la política, de una "nueva" política que no haría sino repetir la tragedia del pensamiento político moderno, incluyendo sus refundaciones post-fundacionalistas ${ }^{31}$. En este sentido, el materialismo salvaje, cuya política podríamos decir, se expresa en el republicanismo salvaje, no funciona constrictiva o prescriptivamente, sino que figura una interrupción, violenta por supuesto, de todo aquello que circula libremente bajo todos estos nombres. No se trata entonces de producir una "nueva" filosofía política, sino de posibilitar una suspensión de las pretensiones de la filosofía y de la teoría sobre la política, una suspensión o interrupción cuya violencia exponga las (endémicas) limitaciones de nuestra naturalizada relación con la política.

De la misma manera, el materialismo salvaje tampoco funciona como una "nueva" ética, aún cuando haya una dimensión ética insoslayable en su horizonte. Se trata, por el contrario, de pensar el materialismo salvaje y su flujo subterráneo, como un socavamiento no solo de los ordenes disciplinarios, sino también de las ontologías regionales y las especialidades académicas, pues

Esa tragedia no es otra que la de su permanente recomienzo y refundación. 
lo que está en juego en este materialismo es el continuo histórico-ontológico de la existencia ${ }^{32}$, y no su organización atributiva según el orden óntico-ontológico tradicional.

Pero esto nos lleva al segundo problema: si el materialismo salvaje no es, sin más, una filosofía política, tampoco se fundaría, en el sentido convencional, en una ontología que sirviera de base sobre la que articular un modelo ideal de república. De ahí entonces la importancia de historizar también el poema lucreciano, pues no se trata de un poema, digamos, en sentido vulgar o moderno, ni menos de un poema romántico o de un canto subjetivo estéticamente acorde con las determinaciones de la complejidad, de la razón y del gusto. Pensar el poema de Lucrecio, en su anacrónica actualidad, implica fracturar los presupuestos de la poética y de la historia que arman el contrato social como reparto de lo sensible, evitando, de paso, que el poema mismo sirva como modelo de figuración de una vida mejor (al modo en que uno podría -y digo podría porque esto también está en discusión- pensar la lectura de Hölderlin y Trakl desarrollada por Martin Heidegger), una vez hayamos sido liberados de las amarras onto-teológicas de la metafísica. Ni filosofía política ni ontología, es decir, ni rendimiento regional ni determinación extra-histórica de la contingencia radical. Por lo tanto, tampoco "poema" como apuesta por la restitución de una esencia extraviada de la lengua, ni mucho menos, uso instrumental del poema, como fundamentación de una determinada comunidad sensible (Volksgemeinschaft). Estas mismas aprehensiones parecieran estar presentes, por ejemplo, en la forma en que Philippe Lacoue-Labarthe cuestiona la mito-poética heideggeriana (como una argucia más arcaica aún que el mismo poema, tan vieja como el mito, muthos $^{33}$ ); en la forma en que Derrida deconstruye la referencia al poema en Heidegger, o en la forma en que Badiou interroga la sutura entre filosofía y poema como característica distintiva de la llamada "edad de los poetas" 34 .

Por supuesto, no estamos sosteniendo que Lezra repita inadvertidamente el gesto heideggeriano, ni que introduzca, subrepticiamente, una revitalización del poema, reflotando de paso la misma edad de los poetas que Badiou se apura en despedir en nombre de una ontología platónico-matemática. Lo que indicamos es la necesidad de detenerse en este complejo entramado de problemas, pues en el se juegan aspectos importantes para pensar el estatuto mismo de un republicanismo salvaje. En efecto,

32 Desde aquí, cabría argumentar, la imagen del pensamiento levianasiano que enfatiza una supuesta prioridad de la ética sobre la ontología se complejiza, pues el “anarquismo' de Levinas supondría no solo un cambio de prioridades, sino una disolución radical tanto de la ética como de la ontología convencionalmente entendidas, las que ya no podrían seguir siendo pensadas según la representación tradicional (metafísica) de la existencia. Cf. M. Abensour, "L'anarchie entre méta-politique et politique", Les cahiers philosophiques de Strasbourg, 14, Strasbourg, 2002. Ver también, A. Liviana Messina, "El otro miedo: Guerra originaria y paz anárquica en Hobbes y Lévinas", Revista Pléyade, 13, 2014, pp. 23-59.

$33 \mathrm{Ph}$. Lacoue-Labarthe, Heidegger and the Politics of Poetry, trad. J. Fort, Chicago, University of Illinois Press, 2007.

34 A. Badiou, The Age of the Poets and Other Writings on TwentiethCentury Poetry and Prose, trad. B. Bosteels, New York, Verso, 2014. si la interrogación derridiana de la función del poema en Heidegger, a propósito de la reciente publicación de Geschlecht III, repara en la sobre-codificación del mismo poema desde la problemática de la re-unión, la pertenencia, el lugar y la destinalidad del ser, su vuelta al hogar, digamos, como fin del extrañamiento y del desarraigo, entonces ¿cómo está leyendo Lezra el poema lucreciano y cómo evita transformarlo en una mera referencia que importa o contrabandea a la dinámica de su construcción argumental una forma soterrada de logocentrismo sustituto? La respuesta a esta pregunta partiría por radicalizar la tensión insuturable entre poema y ontología, haciendo que la aparente vacilación de Lezra al respecto, se decidiera de una manera no convencional, esto es, mediante el reemplazo de la ontología por la historicidad del poema, lo que no es similar a la demanda historicista de los estudiosos clásicos. En efecto, en la diferencia entre historicismo e historicidad se juega una relación crítica con la ontología que habría que seguir pensando para comprender los usos del De rerum natura en el trabajo de Lezra en general. En otras palabras, la misma "ontología materialista" y la noción de "poema" deben ser entendidos como conceptos débiles o defectivos, semi-conceptos, pues de lo contrario, se produciría un efecto obviamente contraproducente.

Pero, por otro lado, esto también abre una interrogación fundamental relativa a la cuestión del lenguaje en la ontología defectiva o débil (no determinativa, abierta a la contingencia radical, no atributiva) de Lezra. Y aquí entonces habría que domiciliar la diferencia irreconciliable con los nuevos materialismos y las ontologías orientadas al objeto $(\mathrm{OOO})^{35}$. Para estas, Lezra pareciera quedar atrapado en una textualidad tributaria, como se dice, del giro lingüístico contemporáneo, es decir, el materialismo salvaje terminaría siendo simplemente una modulación de la relación entre las palabras y las cosas que no habría logrado escapar a la lógica inmaterial del discurso. Sin embargo, la referencia a Lucrecio está tramada por un anacronismo que implica una relación a la materia sin mediación (ni síntesis) ni subordinación a la lógica del significante. Esto es, precisamente, lo que Lezra llama su filología negativa o necrofilología, la que a diferencia de la filología clásica, orientada por la pretensiosa positivización de un origen explicativo, tiende a pensar el sentido de acuerdo con la finitud de su contexto. La necrofilología, en otras palabras, asumiendo la infinitud del contexto, opera como interrupción de la circulación, del sentido y de la traducción, es decir, de la lógica de la equivalencia que define tanto el discurso académico hegemónico, como el discurso hegemónico académico. La necrofilología, en este sentido, es una interrupción de la traducción y de la equivalencia a partir de la postulación de una teoría material de la producción de conceptos débiles y defectuosos, siempre abiertos a los vaivenes de lo real.

Por supuesto, esta historización radical, esta apertura a la contingencia sin revés, esta destitución de la función fundacional del poema, y esta obliteración de los

\footnotetext{
3 Cf. el simposio "On the Nature of Marx's Things" que tuvo lugar el mes de julio del 2020 y que se encuentra publicado en https://syndicate.network/symposia/literature/on-the-nature-of-marxs-things/
} 
rendimientos disciplinarios de la filosofía política o de la filología clásica, nos permiten entender el materialismo salvaje como una práctica material de lectura, que atenta al poema, no lo fetichiza, ni lo reviste con las vestimentas de un monumento cultural: el poema, pensado desde este materialismo sin principios, es la ocurrencia eventual en la que se dan cita, palabras precarias y exiliadas desde la circulación habitual con la materialidad catastrófica de un mundo que no puede ser contenido ni congelado por la fuerza metafísica del concepto.

\section{4.}

Todo esto nos lleva a nuestra última sección relativa a lo que podríamos llamar el poema material de la destrucción. Para tal efecto, quisiéramos volver brevemente a la forma en que el mismo Lezra piensa el republicanismo salvaje como crítica del momento republicano latinoamericano, particularmente en la figura fundacional de Andrés Bello y las jóvenes repúblicas americanas de comienzos del siglo XIX ${ }^{36}$. Nos gustaría reparar no tanto en la labor política inmediata ni en la función universitaria de Bello, sino en su poética fundacional, en particular, en su famosa "Silva a la agricultura de la zona tórrida" $(1826)^{37}$, en la que, al modo de un canto pastoril local, de corte clasicista y utópico, se funda la posibilidad de una vida americana en concierto y armonía con las potencias y los dones de la naturaleza. Por supuesto, la naturaleza de Bello no es todavía la naturaleza de Sarmiento y del liberalismo decimonónico, aquella naturaleza convertida en "recursos naturales", imagen que emerge para perpetuarse en el neo-extractivismo contemporáneo, como renta y propiedad. Se trata, más bien, de un jardín epicúreo y armónico que regula todos sus ciclos bajo la lógica del don y la abundancia. Bástennos una muestra de las primeras estrofas:

¡Salve, fecunda zona,

que al sol enamorado circunscribes

el vago curso, y cuanto ser se anima

en cada vario clima,

acariciada de su luz, concibes!

Tú tejes al verano su guirnalda

de granadas espigas; tú la uva

das a la hirviente cuba;

no de purpúrea fruta, o roja, o gualda,

a tus florestas bellas

falta matiz alguno; y bebe en ellas

aromas miles el viento;

y greyes van sin cuento

paciendo tu verdura, desde el llano

que tiene por lindero el horizonte,

hasta el erguido monte,

de inaccesible nieve siempre cano.

Tú das la caña hermosa,

de do la miel se acendra,

por quien desdeña el mundo los panales;

${ }^{6}$ Cf. República salvaje, op. cit., pp. 11-30.

37 A. Bello, Silvas americanas y otros poemas, Barcelona, Ramón Sopena Ediciones, 1978. tú en urnas de coral cuajas la almendra que en la espumante jícara rebosa; bulle carmín viviente en tus nopales, que afrenta fuera al múrice de Tiro; y de tu añil la tinta generosa émula es de la lumbre del zafiro. El vino es tuyo, que la herida agave para los hijos vierte

del Anahuac feliz; y la hoja es tuya, que, cuando de suave humo en espiras vagarosas huya, solazará el fastidio al ocio inerte. Tú vistes de jazmines el arbusto sabeo, y el perfume le das, que en los festines y la fiebre insana templará a Lieo. Para tus hijos la procera palma su vario feudo cría, y el ananás sazona su ambrosía; su blanco pan la yuca; sus rubias pomas la patata educa; y el algodón despliega el aura leve las rosas de oro y el vellón de nieve. Tendida para ti la fresca parcha en enramadas de verdor lozano, cuelga de sus sarmientos trepadores nectáreos globos y franjadas flores; y para ti el maíz, jefe altanero de la espigada tribu, hincha su grano; y para ti el banano desmaya al peso de su dulce carga; el banano, primero de cuantos concedió bellos presentes Providencia a las gentes de ecuador feliz con mano larga. No ya de humanas artes obligado el premio rinde opimo; no es a la podadera, no al arado deudor de su racimo; escasa industria bástale, cual puede hurtar a sus fatigas mano esclava; crece veloz, y cuando exhausto acaba, adulta prole en torno le sucede.

En efecto, el idílico paraíso americano de Bello, lleno de dones para los cuales no haría falta mucha industria ni trabajo, no solo evoca la fantasía lárica de un paraíso en la tierra, abundante y generoso, armónico aunque bullente, predispuesto para el desarrollo de la vida americana; el poema también funda (o refunda, si uno atiende a las ensoñadas y míticas descripciones de América por los conquistadores y cronistas) poéticamente tanto el nombre como la posibilidad de la vida americana, con la que Bello entiende una vida ajena al tráfago de las influencias extranjeras, cuestión necesaria para "nuestra" autonomía cultural. Algo así imaginan también los fundadores de las jóvenes repúblicas, al menos por algunos años, antes de verse compelidos por la misma dinámica política y económica a rendir los dones naturales en recursos y capital. Esa traducción, si así pudiésemos llamar a dicha conversión, provocaría la devastación no 
del paraíso americano, sino de su imagen idealizada, mostrándonos que la historia regional ha sido siempre la historia de la destrucción y de la profanación. De esto se sigue, por lo tanto, no solo la incongruencia entre el imaginario poético fundacional y la historia efectiva de América Latina, sino también la necesidad de atender al reverso de este Long Poem americano, el reverso de la vida armónica en el jardín de Bello, que como el jardín de Epicuro, constituye el plano en el que se inscribe, con un grado variable de contingencia, el otro poema, el poema de la destrucción y de la catástrofe.

En sus reflexiones sobre la pertinencia de Lucrecio para pensar la cuestión de las nuevas repúblicas, Lezra realiza un comentario extemporáneo sobre la crisis mundial, precipitada por la globalización y por sus procesos de devastación generalizados, como una nueva ocasión para leer a Lucrecio. Nos dice, esta ocasión nos permitiría una nueva relación con la ontología material y su materialismo heteróclito.

Lucrecio regresa, regresamos a Lucrecio, o nos encontramos de nuevo en su compañía (anacrónicamente, algo desincronizados, a destiempo). Es como si estas crisis tan sumamente contemporáneas de la globalización y de la democracia institucional, las crisis en la conceptualización de los "hechos" y de los hechos alternativos, de la verdad y de la posverdad, convocaran en cierto modo el poema milenial; como si un poema que ofrece al sujeto moderno europeo liberarlo de todas y cada una de las supersticiones que sumen al espíritu en la oscuridad estuviera en sintonía con el dinamismo caótico con el que las "humanidades" y lo "humano" llegarían a subsumirse en la "ciencia" cuya forma canta el poema; y la ontología política, en la economía política del mercado global. Es cierto que $D e$ rerum natura nos ofrece la ataraxia; los placeres serenos de la mente que reposa, libre de la superstición, en el jardín epicúreo; pero igual de cierta es la catástrofe con la que termina el poema, la plaga ateniense, el fuego y la furia ${ }^{38}$.

Decimos nosotros, esa crisis develada por la globalización ya siempre estuvo acaeciendo, y la contemporaneidad anacrónica de Lucrecio, que ha estado velada por la predominancia de una mito-poética de la liberación, por el Long Poem latinoamericano como su particular filosofía de la historia, nos debe servir para entender que la destrucción siempre ha sido la condición de posibilidad de la misma historia. En tal caso, no es un hecho menor que el agotamiento de la ficción soberana y del long poem latinoamericano "tome cuerpo", ahora, bajo la forma de un detritus negativo, en el poema "Cadáveres" de Néstor Perlongher (1987) ${ }^{39}$.

Se trata de la entonación de una donación, bajo la forma del "hay" (es gibt, il y a) que inscribe la catástrofe, relacionada con el asesinato y la muerte, al interior de la vida en común, en el pasaje desde una república cuyo simulacro soberano está ya siempre saturado por cadáveres, hacia el desierto de la globalización neoliberal, en el que encontramos la sostenida repetición del mis-

\footnotetext{
8 J. Lezra, República salvaje, op. cit. pp. 29-30.

39 N. Perlongher, Alambres, Buenos Aires, Ediciones Último Reino, 1987. Cf. también, N. Perlongher, "Cadáveres", en Poemas completos (1980-1992), Buenos Aires, Seix Barral, 1997, pp. 117-131.
}

mo verso: "hay cadáveres". En efecto, este poema que implica una interrupción necrofilológica de la semiosis post-dictatorial y sus promesas de duelo y modernización, que demanda una suspensión de los discursos de la reconciliación y del olvido, no renuncia al duelo por la pérdida incuantificable producida por la violencia estatal, sin apuntar a la restitución imaginaria de una comunidad perdida. Se trata de un poema largo, que repite, como decíamos, 56 veces el verso central, "hay cadáveres", para acentuar aún más la presencia material del crimen y la muerte, cuyas huellas -los cadáveres- llenan el espacio vacío del nihilismo, haciendo que la nada se pueble de cuerpos abandonados.

\section{CADÁVERES}

Bajo las matas

En los pajonales

Sobre los puentes

En los canales

Hay Cadáveres

En la trilla de un tren que nunca se detiene

En la estela de un barco que naufraga

En una olilla, que se desvanece

En los muelles los apeaderos los trampolines los malecones Hay Cadáveres

En las redes de los pescadores

En el tropiezo de los cangrejales

En la del pelo que se toma

Con un prendedorcito descolgado

Hay Cadáveres

En lo preciso de esta ausencia

En lo que raya esa palabra

En su divina presencia

Comandante, en su raya

Hay Cadáveres

En las mangas acaloradas de la mujer del pasaporte que se arroja

por la ventana del barquillo con un bebito a cuestas

En el barquillero que se obliga a hacer garrapiñada

En el garrapiñiero que se empana

En la pana, en la paja, ahí

Hay Cadáveres

Precisamente ahí, y en esa richa

de la que deshilacha, $y$

en ese soslayo de la que no conviene que se diga, y

en el desdén de la que no se diga que no piensa, acaso

en la que no se dice que se sepa...

Hay Cadáveres

Empero, en la lingüita de ese zapato que se lía disimuladamente, al

espejuelo, en la

correíta de esa hebilla que se corre, sin querer, en el techo,

patas

arriba de ese monedero que se deshincha, como un buhón,

$$
\mathrm{y}, \sin
$$


embargo, en esa c.... que, cómo se escribía? c. ... de qué?, mas, Con

Todo

Sobretodo

Hay Cadáveres

En el tepado de la que se despelmaza, febrilmente, en la menea de la que se lagarta en esa yedra, inerme en el despanzurrar de la que no se abriga, apenas, sino con un saquito, y en potiche de saquitos, y figurines anteriores, modas pasadas como mejas muertas de las que

\section{Hay Cadáveres}

Se ven, se los despanza divisantes flotando en el pantano: en la colilla de los pantalones que se enchastran, símilmente; en el ribete de la cola del tapado de seda de la novia, que no se casa

porque su novio ha

Hay Cadáveres

"Cadáveres" presenta o hace presente el cadáver como verdad de la historia. En cuyo caso, si el poema de Bello sigue inscrito y re-inaugura una larga tradición mitopoética latinoamericana; tradición asociada con el republicanismo clásico, normativo e identitario, que permitió la ficción soberana de los últimos dos siglos, "Cadáveres" de Perlongher, al modo de una prolongado clinamen, alude a una desviación desde dicha tradición, haciendo aparecer la destrucción y la muerte, el terror y la devastación no como agentes externos a la paz perpetua republicana imaginada por el gran poema latinoamericano, no como efectos imponderables de la crisis contemporánea, sino como potencias de una "naturaleza" que subsume a la historia en sus dinámicas radicales y contingentes, impidiéndonos, a su vez, afirmar el habitar en la figura sacralizada del contrato social o del jardín pletórico. Pensar todo esto es fundamental, sobre todo hoy, cuando el agotamiento de la ficción soberana latinoamericana co-incide con la mundialatinización, bajo las formas teológicas de la soberanía, la pertenencia y la identidad. Por de pronto, esto es también lo que se está tramando en la posibilidad de un republicanismo salvaje, constituido en la precariedad fundamental de la vida y en la potencia incalculable de sus proliferaciones. Prosigue Perlongher:

En eso que empuja

lo que se atraganta,

En eso que traga

lo que emputarra,

En eso que amputa

lo que empala,

En eso que iputa!

Hay Cadáveres

\section{$[\ldots]$}

En el campo

En el campo
En la casa

En la caza

Ahí

Hay Cadáveres

En el decaer de esta escritura

En el borroneo de esas inscripciones

En el difuminar de estas leyendas

En las conversaciones de lesbianas que se muestran la marca de la liga,

En ese puño elástico,

Hay Cadáveres

\section{$[\ldots]$}

Féretros alegóricos!

Sótanos metafóricos!

Pocillos metonímicos!

Ex-plícito!

Hay Cadáveres

Ejercicios
Campañas
Consorcios
Condominios
Contractus
Hay Cadáveres
Yermos o Luengos
Pozzis o Westerleys
Rouges o Sombras
Tablas o Pliegues
Hay Cadáveres

No hay declinación subjetiva, memorial, afectada, en Perlongher. El poema tematiza la materialidad del mundo, el cadáver prolifera, sin economía, como marca indeleble de una violencia más violenta que la ley, pues no solo se trata de la dictadura argentina ni de la guerra, se trata de la forma de ser de la historia, la que linda con el terror, sobre todo allí donde, en nombre de la paz, se reemprende permanentemente el proyecto brutal de la refundación, cuyos costos no son otros que la proliferación de cadáveres. Estos, en efecto, proliferan, como los conejitos de Cortázar ${ }^{40}$, pero no para arruinar una casa, sino para definirla en su plenitud, pues están en todos lados, en la lengua, en las palabras, en los ojos, en las pestañas, en el paisaje y en los lentes con los que miramos.

"Cadáveres" es una variación porteña y extemporánea del De rerum natura, no solo por la instanciación de la destrucción y de la catástrofe, la que llena de restos y sobras el paraíso americano de Bello, sino por el rigor de su verso, el que se resiste a la significación sintética, abriéndose al duelo infinito, imposible de sosegar con las leyes de la reconciliación y de la reparación. "Cadáveres" apunta hacia el espacio poblado de cuerpos estropeados, los que no pueden ser estetizados según las claves hermenéuticas que insisten en hablar de un neo-barroso, como si se tratara de una cuestión de esti-

40 J. Cortázar, "Carta a una señorita de París”, en Bestiario, Buenos Aires, Editorial Sudamericana, 1970, pp. 19-34. 
lo. El neo-barroso del poema, sus referencias barrocas y neo-barrocas son innegables, pero quizás en eso también consista la fuerza indómita del poema, en desarmar la conjugación culturalista de los estilos y mostrarnos al mismo barroco como una proliferación y una serie infinita de pliegues que, lejos del preciosismo conceptual de la historia del arte y de la literatura, muestran el cuerpo roto, el cadáver, como clave enigmática de una relación con los restos que resiste, en su mutismo, su conversión en mercancía o en objeto cultural.

Por supuesto, no se trata de leer literalmente el poema, como si en él se "representara" la violencia militar y su producción industrial de desaparecidos. Los cadáveres nos indican otra cosa que la representación, pues con ellos, los desaparecidos se constituyen en presencia, pero presencia "sin metafísica de la presencia", al modo de restos y fantasmas que, estando ahí, no están; estando ahí, no cuentan, pues son incalculables, incontables, irrepresentables. El poema, en efecto, como canto de la destrucción y de la catástrofe, interrumpe la melodía transicional que define el tono de la reconciliación y el imaginario utópico de la globalización neoliberal. No hay, por lo tanto, promesa en el poema, el mismo poema es una enumeración, una iteración, una crónica no estructurada por un hilo narrativo, sino por la emergencia y proliferación de los cadáveres, los que contaminan todas las dimensiones de la vida, apareciendo entre las cosas, en el cuerpo, en las mucosas, en los objetos, en el paisaje, como paisaje, etc.

"Cadáveres" de Perlongher no puede funcionar como referente para ninguna ontología política, su política, si así pudiésemos hablar, nos llevaría a una reformulación radical de la división de lo sensible, nos abismaría frente al terror de la existencia, sin hacernos ingresar en el sonambulismo de las metáforas destinadas a compensar nuestra falta de fundamento. Por supuesto, "Cadáveres" no sirve para fundar una "nueva" política, pero, quizá por eso mismo, es el poema al que debemos mirar, a pesar de la imposibilidad de usarlo como fundamento, o precisamente gracias a dicha imposibilidad, porque en él se hace posible un pensamiento "a la altura" de nuestro tiempo, un poema capaz de pensar/presentar la destrucción de las repúblicas latinoamericanas, sin repetir el gesto populista de la refundación del contrato o del Pueblo, otra metáfora con la cual recomenzamos el viejo truco de contarnos finales felices. El rigor materialista del poema, como lo quiso Althusser, como lo quiere Lezra, nos demanda demorarnos en él, morar y demorar en el vórtice que este poema, al igual que un huracán, nos promete, aunque sea sin utopías.

\section{Bibliografía}

Abensour, M., "L'anarchie entre méta-politique et politique" en Les cahiers philosophiques de Strasbourg No 14, dossier, Lévinas et la politique, Strasbourg, 2002.

Althusser, L., “Contradicción y sobredeterminación” (notas para una investigación)”, en La revolución teórica de Marx, trad. M. Harnecker, México, Siglo XXI, 1968, pp. 71-106.

-, Écrits philosophiques et politiques, 2 Tomes, Paris, Éditions STOCK/IMEC, 1994.

-, Para un materialismo aleatorio, Pedro Fernández Liria (ed.), Madrid, Arena Libros, 2002.

-, Filosofia y marxismo. Entrevista por Fernanda Navarro, Madrid, Siglo XXI, 2005.

Badiou, A., The Age of the Poets and Other Writings on Twentieth-Century Poetry and Prose, trad. Bruno Bosteels, New York, Verso, 2014.

Bello, A., Silvas americanas y otros poemas, Barcelona, Ramón Sopena Ediciones, 1978.

Benjamin, W., "Para una crítica de la violencia", en Para una crítica de la violencia y otros ensayos. Iluminaciones IV, trad. R. Blatt, España, Taurus, 1991. 24-46.

Castoriadis, C., La institución imaginaria de la sociedad, Barcelona, Tusquets, 2013.

Cortázar, J., "Carta a una señorita de París", en: Bestiario, Buenos Aires, Editorial Sudamericana, 1970, pp. 19-34.

Dastur, F., "Heidegger y Trakl: el paraje occidental y el viaje poético", en Escritura e imagen, 12, 2016, pp. 249-266.

-, "Heidegger and Derrida on Trakl", en Phenomenology and Literature: Historical Perspectives and Systematic Accounts, Pol Vandevelde (ed.), Würzburg: Koenighausen \& Neumann, 2010, pp. 43-57.

Derrida, J., Fuerza de ley. El "fundamento místico de la autoridad”, P. Peñalver y A. Barberá, Madrid, Tecnos, 2008.

-, Heidegger: The Question of Being and History, trad. Geoffrey Bennington, Chicago, The University of Chicago Press, 2016.

-, Geschlecht III. Sexe, race, nation, humanité, Paris, Seuil, 2018.

Deleuze, G., El pliegue. Leibniz y el barroco, trad. J. Vázquez y U. Larraceleta, Barcelona, Paidós, 1989.

-, Lógica del sentido, Barcelona, Paidós, 2005.

Didi-Huberman, G., Ante el tiempo. Historia del arte y anacronismo de las imágenes, trad. A. Oviedo, Buenos Aires, Adriana Hidalgo Editora, 2006.

Esposito, R., Immunitas. Protección y negación de la vida, trad. L. Padilla López, Madrid, Amorrortu, 2004.

Galli, C., Political Spaces and Global War, trad. E. Fay, Minneapolis, University of Minnesota Press, 2010.

Gargarella, R., La sala de máquinas de la constitución, Buenos Aires, Katz Editores, 2014.

Habermas, J., La reconstrucción del materialismo histórico, Madrid, Taurus, 1981.

Heidegger, M., Carta sobre el humanismo, trad. Helena Cortés y Arturo Leyte, Madrid, Alianza editorial, 2013.

Hirschl, R., Towards Juristocracy. The Origins and Consequences of the New Constitutionalism, Cambridge, Massachusetts, Harvard University Press, 2007.

Laclau E. \& Ch. Mouffe, Hegemonía y estrategia socialista. Hacia una radicalización de la democracia, Madrid, Siglo XXI, 1987.

Laclau, E., La razón populista, Buenos Aires, Fondo de Cultura Económica, 2010,

Lacoue-Labarthe, Ph., Heidegger and the Politics of Poetry, trad. J. Fort, Chicago, University of Illinois Press, 2007. 
Lezra, J., Materialismo salvaje. La ética del terror y la república moderna, trad. J. Rodríguez Fernández, Madrid, Biblioteca Nueva, 2012.

-, Untranslating Machines: A Genealogy for the Ends of Global Thought, Londres, Rowman and Littlefield, 2017.

-, On the Nature of Marx's Things, New York, Fordham University Press, 2018.

-, República Salvaje, Santiago, Ediciones Macul, 2019.

Lezra, J. \& L. Blake (eds.), Lucretius and Modernity: Epicurean Encounters across Time and Disciplines, New York, Pelgrave Macmillan, 2016.

Liviana Messina, A., "El otro miedo: Guerra originaria y paz anárquica en Hobbes y Lévinas”, en Revista Pléyade, 13, 2014, pp. 23-59.

Marx, K., Tesis sobre Feuerbach, en Marx, J. Muñoz (ed.), Barcelona, Ediciones Península, 1988.

Montag, W., Althusser and His Contemporaries: Philosophy's Perpetual War, Durham, Duke University Press, 2013.

Morfino, V., El materialismo de Althusser, Santiago de Chile, Palinodia, 2014.

Mouffe, Ch., For a Left Populism, London, Verso, 2018

Perlongher, N., Alambres, Buenos Aires, Ediciones Último Reino, 1987.

-, “Cadáveres", en Poemas completos (1980-1992), Buenos Aires, Seix Barral, 1997, pp. 117-131.

Rancière, J., La lección de Althusser, Buenos Aires, Libros del Zorzal, 2008.

Rodríguez Arriagada, M. \& M. Stacerbaun (comp.), Lecturas de Althusser en América Latina, Santiago de Chile, Doble Ciencia, 2017.

Rorty, R., Contingencia, ironía y solidaridad, Barcelona, Ediciones Paidós, 1991.

Schmitt, C., The Nomos of the Earth in the International Law of Jus Publicum Europaeum, trad. G. L. Ulmen, New York, Telos Press Publishing, 2006.

Simposio "On the Nature of Marx's Things" que tuvo lugar el mes de julio del 2020 y que se encuentra publicado acá: https:// syndicate.network/symposia/literature/on-the-nature-of-marxs-things/

Spanos, W., American Exceptionalism in the Age of Globalization: The Specter of Vietnam, New York, SUNY Press, 2008.

Tarde, G., Monadología y sociología, Buenos Aires, Cactus, 2012.

Villalobos-Ruminott, S., "Acerca de la posibilidad de una democracia salvaje”, Pensamiento al margen, № especial: Infrapolitica $y$ democracia, 2018, pp. 33-63. 